\title{
Neuropsychological status of bipolar I disorder: impact of psychosis
}

Jonathan Savitz, Lize van der Merwe, Dan J. Stein, Mark Solms and Rajkumar Ramesar

\section{Background}

The presence of schizotypal personality traits in some people with bipolar disorder, together with reports of greater cognitive dysfunction in patients with a history of psychotic features compared with patients without such a history, raises questions about the nosological relationship between bipolar disorder with psychotic features and bipolar disorder without psychotic features

\section{Aims}

To test the impact of a history of DSM-IV-defined psychosis on the neuropsychological status of participants with bipolar disorder while statistically controlling for confounding factors such as mood, medication, alcohol misuse/dependence and childhood abuse, and to evaluate the impact of schizotypal personality traits (and thus potential vulnerability to psychotic illness) on the cognitive performance of people with bipolar disorder and their healthy relatives.
\end{abstract}

\section{Method}

Neuropsychological data were obtained for 25 participants with type I bipolar disorder and a history of psychosis, 24 with type I bipolar disorder but no history of psychosis and
61 unaffected relatives. Schizotypal traits were measured with the Schizotypal Personality Scale (STA). Childhood trauma was measured with the Childhood Trauma Questionnaire.

\section{Results}

The group with a history of psychosis performed significantly worse than the healthy relatives on measures of verbal working memory, cognitive flexibility and declarative memory. Nevertheless, the two bipolar disorder groups did not differ significantly from each other on any cognitive measure. Scores on the STA were negatively associated with verbal working and declarative memory, but positively associated with visual recall memory.

\section{Conclusions}

'Psychotic' and 'non-psychotic' subtypes of bipolar disorder may lie on a nosological continuum that is most clearly defined by verbal memory impairment.

\section{Declaration of interest}

None.
A variety of cognitive deficits, especially verbal memory and general executive dysfunction, have been reported in people with bipolar disorder. ${ }^{1}$ Nevertheless, effect sizes are small and findings differ across studies. ${ }^{2}$ Possible confounding variables are mood, medication, substance use and childhood abuse. ${ }^{3,4}$ Extant literature also suggests that a diathesis for the development of psychotic features (in the form of schizotypal personality traits) may have an impact on cognitive function. ${ }^{5}$ Approximately half of all patients with bipolar disorder present with psychotic features as defined by DSM-IV on at least one occasion, ${ }^{6,7}$ and schizotypal personality traits have been noted to be salient in samples of people with the disorder. ${ }^{8-10}$ In line with these data, patients with bipolar disorder reportedly display distinct cognitive profiles according to whether or not they have a history of psychotic features, ${ }^{11}$ although see the study by Bora et al. ${ }^{12}$ This is a profoundly important issue because it goes to the heart of the nosological foundations of psychiatry. Significant differences in neurocognitive function between patients with bipolar disorder and remitted psychosis and those with no history of psychosis, not attributable to medication or another confound, would provide preliminary evidence for a nosological distinction between the two 'subtypes' of bipolar disorder, raising questions about the validity of categorical distinctions between bipolar disorder and schizophrenia-spectrum illness as defined in DSM-IV. ${ }^{6}$

In this study we evaluated the performance of two groups of patients with bipolar disorder, one with and one without a history of psychotic features, on a battery of memory and executive tasks while controlling for mood, antipsychotic medication use, alcohol misuse/dependence and childhood trauma. Further, we examined the relationship between neuropsychological performance and possible predisposition to the development of psychotic features in the form of scores on the Schizotypal Personality Scale (STA). ${ }^{13}$

\section{Method}

\section{Sample}

A cohort of 350 White individuals from 47 South African bipolar disorder pedigrees was recruited between 1997 and 2001 as part of a genetics research project. The criterion for recruitment was the presence of two or more affected first-degree relatives. Thereafter, pedigrees were enlarged if they provided genetically informative information. Probands and their relatives were interviewed with the Structured Clinical Interview for DSM-IV Axis I Disorders (SCID-I) ${ }^{14}$ As in a number of other studies, ${ }^{11,12}$ the lifetime presence or absence of psychotic features was evaluated during the diagnostic interview. Psychotic features were defined as the presence of hallucinations or delusions during manic or depressive episodes. Informed consent and ethics approval for the study was obtained.

In a follow-up study conducted between 2003 and 2005, a battery of neuropsychological tests was administered to 225 of the original participants. Reasons for sample attrition were as follows: remote location, 37 (10.5\%); refusal to participate, 42 (12.0\%); death, 22 (6.3\%); emigration, 18 (5.1\%); and confounding neurological condition (e.g. history of stroke), 6 (1.7\%). Of this cohort, 49 participants were diagnosed with type I bipolar disorder and 61 of their relatives were unaffected. The latter group did not have any psychiatric diagnosis. Twenty-five of the participants with type I bipolar disorder had a positive history of psychosis (bipolar(+P) group) and 24 had no history of 
psychosis (bipolar $(-\mathrm{P})$ group). Patients with a serious medical illness, a neurological disorder or any other condition (such as a head injury) that could affect cognition were excluded from the study. One participant had undergone electroconvulsive therapy approximately 6 weeks prior to the testing.

\section{Psychometric testing}

Well-validated neuropsychological tasks measuring various aspects of executive function and verbal and visual memory were given to the cohort. The mood state of the sample at the time of testing was measured with the Beck Depression Inventory (BDI) and the Altman Self-Rating Mania Scale (ASRM). ${ }^{15,16}$ The neuropsychological assessment took approximately $1 \mathrm{~h}$ per person to complete and was administered in the following order: South African Wechsler Adult Intelligence Scale (SA-WAIS) ${ }^{17}$ general knowledge sub-test (a measure of premorbid functioning); Digit Span forward and reverse (attention and verbal working memory); the Controlled Oral Word Association Test (COWAT) for verbal fluency; the Rey Complex Figure (RCF) test (visual spatial functioning and visual memory); the Stroop Colour-Word test (cognitive control); the Rey Auditory Verbal Learning Test (RAVLT) for verbal learning and memory; and the Wisconsin Card Sorting Test (WCST) for cognitive flexibility and set-shifting. Details of these tests are available in standard texts such as that by Spreen \& Strauss. ${ }^{18}$

For the RCF test, two variables were used in the analysis: RCF recall, which refers to the recall score obtained by the participant after the copy condition, and Snow's correction, which is the recall score controlled for the quality of the initial copy of the diagram. Concerning the RAVLT, the following variables were used in the analysis: learning rate, which is the score obtained in trial 1 subtracted from the score obtained in trial 5; total recall, which is the sum of the score obtained on the first five trials; and recognition, which refers to the ability of the participant to recognise the words that were learned after a distracter - in this case the WCST. Two variables were used from the Stroop test: number of words, which refers to the number of words read correctly during the interference condition of the task, and number of errors made by the participant during the interference condition. Four selfexplanatory variables were derived from the WCST: number of categories obtained, trials taken to complete the first category, number of perseverative errors and failure to maintain cognitive set.

The BDI has been shown to be a reliable (test-retest $r=0.74-$ 0.93 ) and valid measure of depression. ${ }^{15}$ Scores of 10-18, 19-29 and 30 or more are indicative of mild, moderate and severe depression respectively. The ASRM correctly classified $85.5 \%$ of patients with mania (scores of 6 or more) and $87.3 \%$ of those without mania in the test development sample. The ASRM shows good test-retest reliability $(r=0.86-0.89)$ and concurrent validity with other mania scales $(r=0.718$ and $r=0.766) .{ }^{16}$

Childhood abuse was measured with the Childhood Trauma Questionnaire (CTQ), ${ }^{19}$ a validated and widely used self-report instrument for both clinical and non-clinical populations. Correlations with therapist ratings of abuse were reported to be statistically significant for all five CTQ sub-scales (emotional, physical and sexual abuse, emotional and physical neglect), ranging from 0.36 to $0.75 .^{18}$ In line with these data, Prescott et al found that actual observations of child-parent interactions correlate well with self-reported recollections of punitive experiences. ${ }^{20}$

Schizotypal personality traits were measured with the STA, ${ }^{13}$ which is modelled on DSM-III criteria for schizotypal personality disorder. Unlike the categorical view of illness represented by the DSM, however, the STA makes the assumption that schizotypal traits, and therefore predisposition to psychotic breakdown, are a continuously distributed phenomenon in the population, and therefore the scale can be used on a normal population. Scores on the questionnaire range from 0 to 37 . The scale has proved to discriminate well between people with a history of psychotic features and control groups, and test-retest correlations of 0.64 after 4 years have been reported. ${ }^{21}$ It has also been the subject of at least three independent principal component analyses which have identified three or four factors variously labelled as 'magical thinking', 'unusual perceptual experiences'; 'paranoid suspiciousness' and 'social anxiety. ${ }^{21}$

\section{Procedure}

The majority of individuals were tested during the day in their own homes; a small number of study participants were assessed in a counselling room at the Division of Human Genetics at the University of Cape Town. Participants were in a stable condition, few having being recently hospitalised. Approximately 180 of the neuropsychological assessments were conducted by a neuropsychologist (J.S.). The balance were conducted by a psychiatric nurse and two graduate students who were trained in the administration of the task.

\section{Statistical analysis}

The statistical program R (www.r-project.org) was used for all statistical analyses. Because the distributions of some of the neuropsychological task scores were skewed, all scores are summarised with median and range. Most of the scales, such as RAVLT total recall, could be analysed as continuous variables, whereas three variables were discrete (counts) with a built-in maximum score of less than 10. All continuous scores were transformed to an approximate standard normal distribution with quantile normalisation as described by Pilia et al. ${ }^{22} \mathrm{~A}$ graph comparing the means of the unadjusted transformed (quantile-normalised) continuous scores between the diagnostic groups was created to illustrate their relative sizes (Fig. 1).

We used generalised linear mixed-effects models to derive all test results reported here, namely tests for equality of means of diagnostic groups for demographic variables, as well as neuropsychological task scores and also the tests of association between neuropsychological test scores and STA. These models are complex because data from family members are dependent and require special methods to obtain valid significance tests. We therefore had to adjust our models by including family membership as a random effect, to control for the fact that some participants were related to one another. Not doing so can result in spuriously strong measures of association because related persons might obtain similar values owing to their shared genetic and environmental background. We also adjusted the models for some or all of the following variables (as fixed covariates): age, gender, total CTQ score, antipsychotic medication use, SCID-defined alcohol misuse or dependence, and self-rated depression scores as measured by the BDI.

Generalised linear models enable one to model variables with different distributions, and therefore one does not need to assume underlying normality for all variables used. The transformed continuous variables were modelled as normal (Gaussian) distributions. The binomial distribution was used for variables with a built-in maximum score: Stroop errors, WCST number of categories and WCST failure to maintain cognitive set. We used the Poisson distribution to model the number of hospitalisations.

A separate model was used to compare each variable (demographic and neuropsychological) simultaneously between the three diagnostic groups. For the neuropsychological variables, a second model was used to test their association with STA. Each 


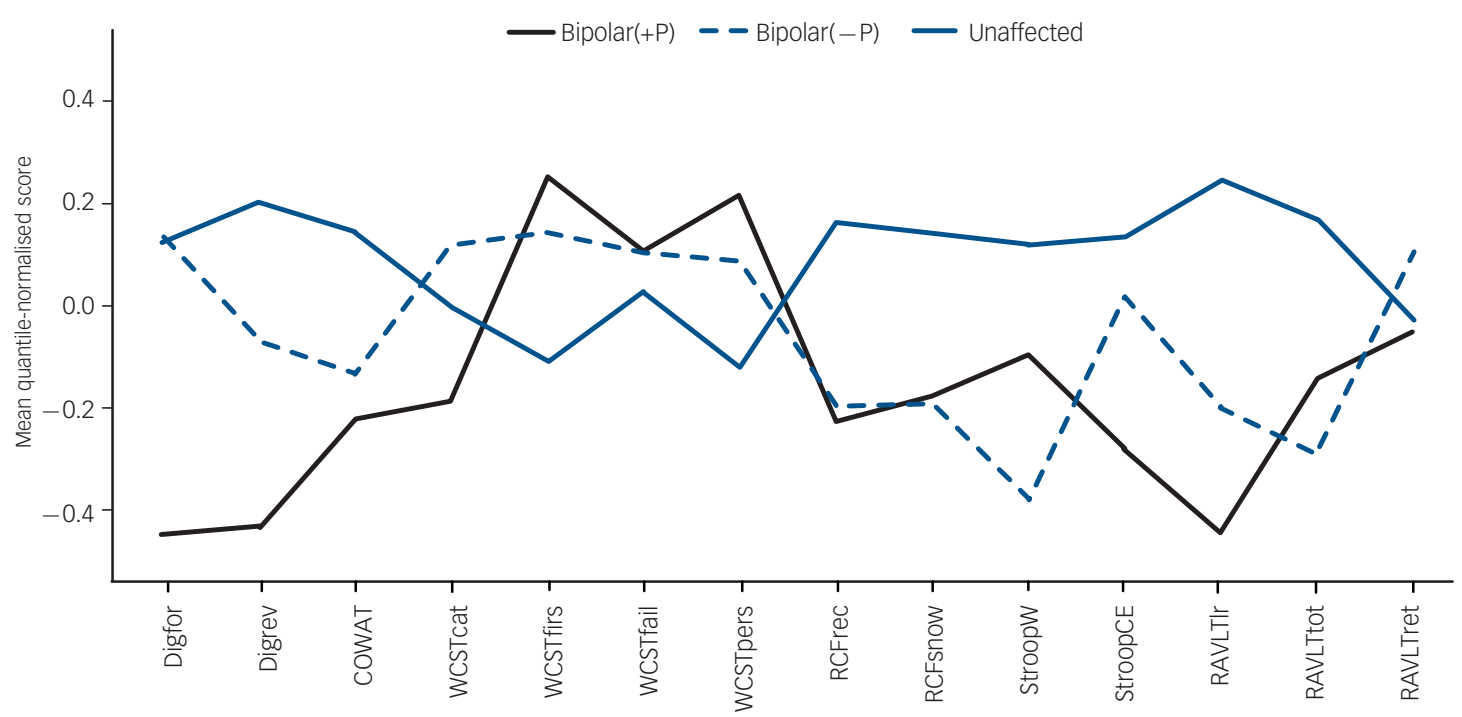

Fig. 1 Unadjusted means of quantile-normalised scores on neuropsychological tasks across the three diagnostic groups: bipolar disorder with psychosis (bipolar(+P)), bipolar disorder without psychosis (bipolar(-P)) and unaffected relatives. COWAT, Controlled Oral Word Association Test; Digfor, Digit Span forwards; Digrev, Digit Span reverse; RAVLT, Rey Auditory Verbal Learning Test (Ir, learning rate; rec, recognition; tot, total recall); RCF, Rey Complex Figure (rec, recall; snow, Snow's correction); StroopW, Stroop number of words; StroopCE, Stroop number of errors; WCST, Wisconsin Card Sorting Test (cat, number of categories; fail, failure to maintain cognitive set; firs, trials to complete first category; pers, perseverative errors).

\begin{tabular}{|c|c|c|c|c|c|}
\hline & $\begin{array}{l}\text { Bipolar }(+P) \\
\quad(n=25)\end{array}$ & $\begin{array}{l}\text { Bipolar }(-P) \\
\qquad(n=24)\end{array}$ & $\begin{array}{l}\text { Unaffected } \\
\qquad(n=61)\end{array}$ & $P$ & Summary of significant difference \\
\hline Age, years: mean (s.d.) & $45.2(13.4)$ & $50.8(16.3)$ & $50.7(18.9)$ & 0.3718 & \\
\hline Age at onset, years: mean (s.d.) & $24.3(8.5)$ & $30.2(13.7)$ & & $0.1469^{a}$ & \\
\hline Gender, male: $n(\%)$ & $11(44)$ & $14(58)$ & $33(54)$ & $N A^{b}$ & \\
\hline $\begin{array}{l}\text { WAIS general knowledge score: } \\
\text { mean (s.d.) }\end{array}$ & $11.0(1.4)$ & 11.5 & $11.1(1.7)$ & $0.6263^{\mathrm{a}}$ & \\
\hline Education, years: mean (s.d.) & $14.4 \quad(2.4)$ & $16.2(3.5)$ & $15.6(3.7)$ & 0.2591 & \\
\hline \multicolumn{6}{|l|}{ Medication, $n$ (\%) } \\
\hline Antipsychotic & $5(20.0)$ & $7(29.2)$ & $0(0.0)$ & $N A^{b}$ & $\begin{array}{l}\text { Bipolar }(-P)>\text { bipolar }(+P)(P=0.0317) ; \text { bipolar }(+P)>\text { unaffected } \\
(P<0.0001) \text {; } \\
\text { Bipolar }(-P)>\text { unaffected }(P<0.0001)\end{array}$ \\
\hline Antidepressant & $13(52)$ & $11(46)$ & $2(3)$ & $N A^{b}$ & $\begin{array}{l}\text { Bipolar }(+P)>\text { unaffected }(P=0.0001) \text {; bipolar }(-P)>\text { unaffected } \\
(P<0.0003)\end{array}$ \\
\hline Lithium & $7(28)$ & $11(45)$ & $0(0.0)$ & $N A^{b}$ & $\begin{array}{l}\text { Bipolar }(+P)>\text { unaffected }(P<0.0001) \text {; bipolar }(-P)>\text { unaffected } \\
(P<0.0001)\end{array}$ \\
\hline Mood stabiliser & $15(60)$ & $6(25)$ & $0(0.0)$ & $N A^{b}$ & $\begin{array}{l}\text { Bipolar }(+P)>\text { unaffected }(P<0.0001) \text {; bipolar }(-P)>\text { unaffected } \\
(P<0.0001)\end{array}$ \\
\hline Alcohol misuse/dependence, $n$ (\%) & $6(24)$ & $3(13)$ & $0(0)$ & $N A^{b}$ & Bipolar $(+P)>$ unaffected $(P<0.0117)$ \\
\hline $\begin{array}{l}\text { Hospitalisations for depression, } \\
n: \text { mean (s.d.) }\end{array}$ & $1.8(2.2)$ & $1.7(1.9)$ & $0(0.0)$ & $N A^{c}$ & \\
\hline $\begin{array}{l}\text { Hospitalisations for mania, } \\
n \text { : mean (s.d.) }\end{array}$ & $4.2(4.9)$ & $2.3(2.4)$ & $0(0.0)$ & $N A^{C}$ & \\
\hline \multicolumn{6}{|l|}{ Psychometric scores, mean (s.d.) } \\
\hline Depression (BDI) & $11.3(9.3)$ & $8.7(10.6)$ & $4.4(4.1)$ & $<0.0001$ & $\begin{array}{l}\text { Bipolar }(+P)>\text { unaffected }(P=0.0001) \text {; bipolar }(-P)>\text { unaffected } \\
(P=0.0072)\end{array}$ \\
\hline Hypomania (ASRM) & $3.2(3.0)$ & $3.7(4.2)$ & $2.5(2.6)$ & 0.2411 & \\
\hline CTQ sexual abuse & $11.3(6.9)$ & $7.0(4.0)$ & $6.9(3.7)$ & $0.0038^{a}$ & $\begin{array}{l}\text { Bipolar }(+P)>\text { bipolar }(-P)(P=0.0062) ; \text { bipolar }(+P)>\text { unaffected } \\
(P=0.0014)\end{array}$ \\
\hline CTQ total abuse & $48.8(20.2)$ & $44.4(18.5)$ & $36.3(9.3)$ & $0.0288^{a}$ & Bipolar $(+P)>$ unaffected $(P=0.0123)$ \\
\hline Schizotypy (STA) & $15.2(6.7)$ & $11.9(8.8)$ & $7.4(4.7)$ & $0.0020^{\mathrm{a}}$ & $\begin{array}{l}\text { Bipolar }(+P)>\text { unaffected }(P=0.0001) \text {; bipolar }(+P)>\text { bipolar }(-P) \\
(P=0.0400)\end{array}$ \\
\hline \multicolumn{6}{|c|}{$\begin{array}{l}\text { ASRM, Altman Self-Rating Mania Scale; BDI, Beck Depression Inventory; bipolar(+P), bipolar disorder with positive history of psychosis; bipolar(-P), bipolar disorder with no } \\
\text { history of psychosis; CTQ, Childhood Trauma Questionnaire; NA, not available; STA, Schizotypal Personality Scale; WAIS, Wechsler Adult Intelligence Scale. } \\
\text { a. Transformed variable tested. } \\
\text { b. Dichotomous (binomial) variable tested, so global P-value not available. } \\
\text { c. Poisson counts tested, so global P-value not available. }\end{array}$} \\
\hline
\end{tabular}


model provides an estimate, standard error and probability value for the association between the modelled variable or score and each of the variables included in the model. The estimates and all other statistics are adjusted for each other. Because estimates of effects and their standard errors based on quantile-normalised variables (as well as those based on the binomial distribution) cannot be meaningfully interpreted, only the directions of the effects are given, not the estimates. Similarly, the complexity of these models means that statistics (global probability values) for the simultaneous testing of the three diagnostic groups are not provided.

\section{Results}

\section{Demographic and clinical data}

Demographic and clinical data are summarised in Table 1. At the time of testing, patients with a history of psychosis (bipolar $(+\mathrm{P})$ group) and to a lesser extent the patients without such history (bipolar $(-\mathrm{P})$ group) were, on average, significantly more depressed than their unaffected relatives $(P=0.0001$ and $P=0.0072$ respectively). The mood states as assessed with the BDI and ASRM across the groups are shown in Table 2. The bipolar $(+\mathrm{P})$ group reported more childhood trauma, including sexual abuse, than both the bipolar $(-\mathrm{P})$ group $(P=0.0062)$ and unaffected individuals $(P=0.0014)$. They also scored higher on self-reported schizotypy than both the bipolar $(-\mathrm{P})$ group

\begin{tabular}{|lccc|}
\hline Table 2 Mood state of sample at time of testing & \\
\hline Mood state & $\begin{array}{c}\text { Bipolar(+P) } \\
n(\%)\end{array}$ & $\begin{array}{c}\text { Bipolar(-P) } \\
n(\%)\end{array}$ & $\begin{array}{c}\text { Unaffected } \\
\text { relatives } \\
n(\%)\end{array}$ \\
\hline Euthymic & $11(44)$ & $16(67)$ & $51(84)$ \\
\hline Mildly depressed & $9(36)$ & $6(25)$ & $2(3)$ \\
\hline Moderately depressed & $4(16)$ & $1(4)$ & $2(3)$ \\
\hline Severely depressed & $1(4)$ & $1(4)$ & $0(0)$ \\
\hline Hypomanic & $8(32)$ & $8(33)$ & $7(11)$
\end{tabular}

Bipolar(+P), bipolar disorder with positive history of psychosis; bipolar(-P), bipolar disorder with no history of psychosis
$(P=0.0400)$ and unaffected relatives $(P=0.001)$. Participants in the bipolar $(+\mathrm{P})$ group were also more likely than healthy controls to have a history of alcohol misuse or dependence $(P=0.0117)$.

The observed differences between the study groups on chronological age, age at onset, gender ratio, SA-WAIS general knowledge scores, years of education and self-reported hypomania were not significant. There was, however, a significant difference between the two bipolar disorder groups in the numbers of people taking antipsychotic medication $(P=0.0317)$, but not any other class of medication.

\section{Neuropsychological data}

Table 3 shows the median and range of the neuropsychological task scores in the three groups. Figure 1 shows the means across diagnostic groups of the unadjusted, transformed, neuropsychological task scores. These scores provide an indication of the relative effect sizes in the form of standard deviations from the mean. However, these are unadjusted scores; standard errors are therefore not shown on the graph since these error bars would not correspond to differences between the covariate-adjusted means.

Table 4 contains the probability values for pairwise tests of equality in neuropsychological task performance across the groups. These tests were adjusted for age, gender, BDI score, CTQ total abuse score, antipsychotic medication, alcohol misuse/dependence, other pairwise comparisons and family relatedness. Where a significant difference was found, the direction of the effect is shown. Because these tests were applied to transformed scores, the effect sizes (and their standard errors) cannot be interpreted meaningfully and are therefore not given.

There was no statistically significant difference between the three study groups on Digit Span forward, visual memory $(\mathrm{RCF})$ and verbal fluency (COWAT). The bipolar $(+\mathrm{P})$ group performed significantly worse than their unaffected relatives on the RAVLT learning rate $(P=0.0025)$, total recall $(P=0.0132)$ and recognition sub-tests $(P=0.0195)$ and on the perseverative score sub-scale of the WCST $(P=0.0327)$, as well as the reverse Digit Span $(P=0.0066)$. The bipolar $(-\mathrm{P})$ group only differed significantly from unaffected relatives on the learning rate sub-test of the RAVLT $(P=0.0383)$. Although the bipolar $(-\mathrm{P})$ group

\begin{tabular}{|c|c|c|c|c|c|c|}
\hline & \multicolumn{2}{|c|}{ Bipolar(+P) } & \multicolumn{2}{|c|}{ Bipolar(-P) } & \multicolumn{2}{|c|}{ Unaffected relatives } \\
\hline & Median & Range & Median & Range & Median & Range \\
\hline \multicolumn{7}{|l|}{ Digit Span } \\
\hline Forward & 8 & $5-13$ & 10 & $6-13$ & 10 & $4-14$ \\
\hline Reverse & 5 & $3-10$ & 6 & $3-12$ & 7 & $2-12$ \\
\hline COWAT & 36 & $14-57$ & 39 & $9-62$ & 39 & $20-67$ \\
\hline \multicolumn{7}{|l|}{ Rey Complex Figure } \\
\hline Recall & 20 & $4-31$ & 19 & $8-34$ & 24 & $4-35$ \\
\hline Snow's correction & 56 & $11-100$ & 52 & $24-94$ & 69 & $10-97$ \\
\hline \multicolumn{7}{|l|}{ RAVLT } \\
\hline Learning rate ${ }^{a}$ & 4 & $0-8$ & 5 & $1-9$ & 6 & $1-11$ \\
\hline Total recall & 47 & $20-66$ & 43 & $15-65$ & 49 & $25-69$ \\
\hline Recognition & 10 & $0-15$ & 8 & $3-15$ & 11 & $1-15$ \\
\hline \multicolumn{7}{|l|}{ Stroop task } \\
\hline Number of words & 95 & 50-112 & 89 & $42-112$ & 104 & $44-112$ \\
\hline Errors & 1 & $0-8$ & 2 & $0-7$ & 2 & $0-8$ \\
\hline \multicolumn{7}{|l|}{ WCST } \\
\hline Number of categories & 3 & $0-5$ & 4 & $0-5$ & 3 & $0-5$ \\
\hline Trials to complete first category & 12 & $11-64$ & 11 & $11-64$ & 11 & $10-64$ \\
\hline Perseverative errors & 14 & $2-75$ & 9 & $5-86$ & 9 & $0-45$ \\
\hline Failure to maintain cognitive set & 0 & $0-2$ & 0 & $0-3$ & 0 & $0-3$ \\
\hline
\end{tabular}




\begin{tabular}{|c|c|c|c|c|}
\hline & $\begin{array}{c}\text { Bipolar(+P) v. bipolar }(-\mathrm{P}) \\
P\end{array}$ & $\begin{array}{c}\text { Bipolar }(+P) v . \text { unaffected } \\
P\end{array}$ & $\begin{array}{c}\text { Bipolar }(-P) \text { v. unaffected } \\
P\end{array}$ & Nature of significant difference \\
\hline \multicolumn{5}{|l|}{ Digit Span } \\
\hline Forward & 0.1087 & 0.1345 & 0.8748 & \multirow[b]{2}{*}{ Bipolar $(+\mathrm{P})<$ unaffected } \\
\hline Reverse & 0.1608 & $0.0066^{* *}$ & 0.1307 & \\
\hline COWAT & 0.9547 & 0.6142 & 0.6296 & \\
\hline \multicolumn{5}{|l|}{ Rey Complex Figure } \\
\hline Recall & 0.6605 & 0.1342 & \multicolumn{2}{|l|}{0.2528} \\
\hline Snow's correction & 0.6735 & 0.5757 & \multicolumn{2}{|l|}{0.3418} \\
\hline \multicolumn{5}{|l|}{ RAVLT } \\
\hline Learning rate & 0.2004 & $0.0025^{* *}$ & $0.0383^{*}$ & $\begin{array}{c}\text { Both bipolar }(+\mathrm{P}) \text { and bipolar }(-\mathrm{P}) \\
<\text { unaffected }\end{array}$ \\
\hline Total recall & 0.2683 & $0.0132^{*}$ & 0.1084 & Bipolar $(+P)<$ unaffected \\
\hline Recognition & 0.2875 & $0.0195^{\star}$ & 0.1543 & Bipolar $(+\mathrm{P})<$ unaffected \\
\hline \multicolumn{5}{|l|}{ Stroop task } \\
\hline Number of words & 0.5464 & 0.4466 & 0.1202 & \multirow[b]{2}{*}{ Bipolar $(+\mathrm{P})<$ unaffected } \\
\hline Errors & 0.1250 & $0.0350^{*}$ & 0.4213 & \\
\hline \multicolumn{5}{|l|}{ WCST } \\
\hline Number of categories & 0.0951 & 0.5387 & 0.2243 & \multirow{4}{*}{ Bipolar $(+\mathrm{P})<$ unaffected } \\
\hline Trials to complete first category & 0.8717 & 0.7622 & 0.8851 & \\
\hline Perseverative errors & 0.2649 & $0.0327^{*}$ & 0.2718 & \\
\hline Failure to maintain cognitive set & 0.9172 & 0.3373 & 0.2888 & \\
\hline \multicolumn{5}{|c|}{$\begin{array}{l}\text { Bipolar(+P), bipolar disorder with positive history of psychosis; bipolar(-P), bipolar disorder with no history of psychosis; COWAT, Controlled Oral Word ASsociation Test; RAVLT, } \\
\text { Rey Auditory Verbal Learning Test; WCST, Wisconsin Card Sorting Test. } \\
\text { a. Tests adjusted for age, gender, Beck Depression Inventory score, Childhood Trauma Questionnaire total abuse score, antipsychotic medication, alcohol misuse, other pairwise } \\
\text { comparisons and family relatedness. } \\
{ }^{*} P<0.05 ; * * P<0.01 \text {. }\end{array}$} \\
\hline
\end{tabular}

performed better than the bipolar $(+\mathrm{P})$ group, the difference did not reach statistical significance for any of the neuropsychological measures (Table 4). The bipolar $(+\mathrm{P})$ group made fewer errors on the Stroop task than their unaffected counterparts $(P=0.0350)$ but did not differ significantly from the $\operatorname{bipolar}(-\mathrm{P})$ group $(P=0.1250)$ (Table 4).

\section{Schizotypal personality traits and cognitive performance}

After adjusting for the covariates age, gender, alcohol misuse/ dependence and BDI score, we found a significant negative association between STA scores and reverse Digit Span $(P=0.0375)$, as well as RAVLT learning rate $(P=0.0307)$. A trend towards significance (negative association) was seen with respect to the number of colour words obtained on the Stroop task $(P=0.0647)$. There was also a significant positive association between STA scores and visual memory as measured by the RCF $(P=0.0218)$ (Table 5).

After adjusting for the previously mentioned covariates, as well as total CTQ score and antipsychotic medication use, the negative association between STA scores and the reverse Digit Span score still held $(P=0.0468)$ and the observed negative

\begin{tabular}{|c|c|c|c|}
\hline Task & $P^{\mathrm{a}}$ & $P^{\mathrm{b}}$ & Direction of association \\
\hline \multicolumn{4}{|l|}{ Digit Span } \\
\hline Forward & 0.2586 & 0.3149 & \multirow[b]{2}{*}{ Negative } \\
\hline Reverse & $0.0375^{*}$ & $0.0468^{*}$ & \\
\hline COWAT & 0.4605 & 0.5086 & \\
\hline \multicolumn{4}{|l|}{ Rey Complex Figure } \\
\hline Recall & $0.0218^{*}$ & $0.0125^{*}$ & Positive \\
\hline Snow's correction & 0.0781 & $0.0386^{*}$ & Positive \\
\hline \multicolumn{4}{|l|}{ RAVLT } \\
\hline Learning rate & $0.0307^{*}$ & 0.0576 & \multirow[t]{3}{*}{ Negative } \\
\hline Total recall & 0.3257 & 0.1608 & \\
\hline Recognition & 0.6636 & 0.4494 & \\
\hline \multicolumn{4}{|l|}{ Stroop task } \\
\hline Number of words & 0.0647 & 0.1181 & \\
\hline Errors & 0.7809 & 0.6563 & \\
\hline \multicolumn{4}{|l|}{ WCST } \\
\hline Number of categories & 0.8462 & 0.9657 & \\
\hline Trials to complete first category & 0.7547 & 0.9829 & \\
\hline Perseverative errors & 0.0935 & 0.0805 & \\
\hline Failure to maintain cognitive set & 0.8615 & 0.9240 & \\
\hline \multicolumn{4}{|c|}{$\begin{array}{l}\text { COWAT, Controlled Oral Word Association Test; RAVLT, Rey Auditory Verbal Learning Test; WCST, Wisconsin Card Sorting Test. } \\
\text { a. Adjusted for age, gender, Beck Depression Inventory score, alcohol misuse/dependence and family relatedness. } \\
\text { b. Additionally adjusted for antipsychotic medication use and Childhood Trauma Questionnaire total abuse score. } \\
{ }^{* P<0.05} \text {. }\end{array}$} \\
\hline
\end{tabular}


relationship between the RAVLT learning rate and STA scores showed a trend towards significance $(P=0.0576)$. Once again there was a significant positive relationship between STA scores and visual memory as evinced by the RCF test.

\section{Discussion}

\section{Demographic and clinical data}

The trend towards a younger age at onset of bipolar disorder in the group with a history of psychosis compared with the group without such a history (mean 24.3 years $v .30 .2$ years) is congruent with much of the published research. ${ }^{23}$ The literature also notes an association between exposure to childhood abuse and an earlier age at illness onset. ${ }^{24}$ In line with these data, our bipolar $(+\mathrm{P})$ group had higher levels of self-reported childhood trauma, including sexual abuse, than the bipolar $(-\mathrm{P})$ group and unaffected counterparts. This result adds to a growing literature detailing the relationship between childhood abuse and vulnerability to the development of psychotic features (reviewed by Read et $\left.a l^{25}\right)$. Most of this work has focused on psychosis in the context of schizophrenia. In one of the few exceptions, Neria et al reported that $40 \%$ of those in their first-admission psychotic bipolar disorder sample had been physically assaulted in the past, ${ }^{26}$ and patients with bipolar disorder who were exposed to childhood sexual abuse were more likely to present with hallucinations than their non-abused counterparts. ${ }^{27}$ Given our results, we suggest that greater scrutiny of the role of childhood abuse in the development of bipolar disorder with psychotic features is warranted in future studies.

Startup found an association between self-reported exposure to childhood abuse and schizotypy as measured by the OxfordLiverpool Inventory of Feelings and Experiences in volunteers from a psychology department. ${ }^{28}$ A similar association between schizotypal personality disorder and early maltreatment, especially neglect, has been noted. ${ }^{29}$ In our study, those in the bipolar $(+\mathrm{P})$ group not only reported more abuse, but displayed higher levels of schizotypal personality traits compared with the bipolar $(-\mathrm{P})$ group $(P=0.0400)$. We are aware of three studies that have addressed the issue of schizotypal personality traits in bipolar disorder. Rossi et al noted levels of self-reported schizotypal personality traits in a clinically stabilised, manic bipolar disorder sample that were similar to those in a sample of patients with schizophrenia, and higher than those of healthy controls. ${ }^{8}$ Heron et al found that a euthymic bipolar disorder cohort scored midway between a schizophrenia cohort and a background control group on the King's Schizotypy Questionnaire, but patients with bipolar disorder with and without a history of psychotic features did not differ on the questionnaire. ${ }^{9}$ On the other hand, Schurhoff et al assessed schizotypal traits in first-degree relatives of probands with schizophrenia, psychotic bipolar disorder and non-psychotic bipolar disorder: the schizophrenia and psychotic bipolar disorder relative groups did not differ on the Schizotypal Personality Questionnaire (SPQ), but the relatives of psychotic bipolar disorder probands scored significantly higher on the disorganisation sub-scale of the SPQ than the non-psychotic relative group. $^{10}$

These data are also partially consistent with family studies, which have demonstrated that the rates of schizotypal traits in relatives of patients with psychotic bipolar disorder, but not non-psychotic bipolar disorder, approximate those found in relatives of people with schizophrenia. ${ }^{30}$ Similarly, a longitudinal study reported that $35 \%$ of those scoring highly on a self-report measure of schizotypal personality traits developed various affective disorders, including bipolar disorder, after a 10-year hiatus. ${ }^{31}$
The greater usage of antipsychotics in our bipolar $(-\mathrm{P})$ group probably reflects the broadening scope of conditions other than psychosis for which these drugs appear to be useful. Various types of antipsychotic medication have shown promise as mood stabilisers or antidepressants in bipolar disorder. ${ }^{32}$ Congruent with this phenomenon, neither the Glahn et al nor the Bora et al samples were characterised by an excess of antipsychotic use among patients with bipolar disorder and a history of psychosis. ${ }^{11,12}$

\section{Neuropsychological findings}

\section{Working memory}

We are aware of at least five studies that have reported deficiencies in digit span performance in people with remitted bipolar disorder. ${ }^{1,2}$ Further, Ferrier et al noted impaired reverse digit span, as well as spatial span, as measured by the Cambridge Automated Test Battery (CANTAB), in first-degree relatives of patients with bipolar disorder. ${ }^{33}$ Our finding of significantly poorer verbal working memory performance in the bipolar $(+\mathrm{P})$ group is potentially important given the salience of this problem in schizophrenia. Comprehensive literature reviews and meta-analyses have noted that working memory dysfunction is a core feature of schizophrenia. ${ }^{34,35}$ A recent meta-analysis has also suggested that the deficit extends to first-degree relatives of people with schizophrenia. ${ }^{36}$ In fact, Mitropolou et al have argued that working memory impairment is the key cognitive deficit in schizophrenia-spectrum disorders. ${ }^{37}$ On the basis of the schizophrenia literature, and our results showing the Digit Span test to most clearly differentiate the bipolar $(+\mathrm{P})$ group from the bipolar $(-\mathrm{P})$ and control groups (Fig. 1), it seems a reasonable hypothesis that a disruption in working memory performance may be peculiar to, or at least more salient in, bipolar disorder cases with a history of psychotic features.

One difficulty with our hypothesis lies in the fact that patients with type II bipolar disorder, who rarely have a history of psychotic features, have also been reported to have working memory impairments as measured by reverse Digit Span. ${ }^{38}$ Nevertheless, the sample in question might have been unusual in that approximately $20 \%$ of participants had a history of psychotic symptoms. Moreover, the sample also showed forward Digit Span performance deficits, raising the possibility that their working memory impairment was secondary to a phonological loop dysfunction. Of note is the study by Taylor Tavares et al which reported no significant spatial working memory impairment associated with type II bipolar disorder. ${ }^{39}$

\section{Verbal memory}

The significantly poorer performance of both bipolar disorder groups on the learning rate sub-test of the RAVLT $(P=0.025$ and $P=0.0383)$ is consistent with much of the literature. ${ }^{1,2,40}$ The greater impairment in performance among the bipolar $(+\mathrm{P})$ group, who also performed less well than healthy relatives on the total recall scale of the RAVLT $(P=0.0132)$, is also consistent with the sparse literature on the topic.

Martinez-Aran et al found that patients with remitted bipolar disorder and a history of psychosis performed worse than healthy controls on the California Verbal Learning Test (CVLT), ${ }^{41}$ but the impact of antipsychotic medication on performance in this sample is a matter of debate. A follow-up study by the same group $(n=35$ and $n=30$ respectively) again emphasised the association between a history of psychotic features and verbal memory impairment. ${ }^{42}$ On the other hand, the euthymic bipolar disorder sample of Kieseppa et al displayed CVLT-defined verbal learning and memory deficits compared with healthy controls, ${ }^{43}$ but fractionating the sample into patients with $(n=20)$ or without $(n=6)$ a history of 
psychotic features did not yield significant differences between the two bipolar disorder subgroups.

Bora et al administered various tests of executive and memory function, including the RAVLT. ${ }^{12}$ Participants with bipolar disorder who had a history of psychosis $(n=40)$ performed worse than controls on the recall sub-tests of the RAVLT, but did not differ significantly from their counterparts with no history of psychosis $(n=25)$. Although Glahn et al did not report significant verbal memory performance differences between their two groups, ${ }^{11}$ approximately half of the sample were ill at the time of testing and it is unclear how this affected the results of their study.

\section{Cognitive control}

Impaired performance on the Stroop task, a measure of cognitive control (the ability to suppress prepotent responses to stimuli), has been reported in individuals with bipolar disorder in remission (e.g. Martinez-Aran et $a l^{41}$ and Ali et $a l^{44}$ ). This Stroop-induced executive dysfunction has also been reported to extend to the unaffected relatives of bipolar disorder probands, ${ }^{45}$ and we recently observed an increase in Stroop errors in people with major depressive disorder who were members of an extended pedigree with bipolar-spectrum illness. ${ }^{46}$ In light of these data, our finding that the bipolar $(+\mathrm{P})$ group actually made fewer errors than healthy relatives on the Stroop task seems unlikely to be genuine unless it is reflective of a compensatory strategy on the part of the bipolar $(+\mathrm{P})$ group (i.e. reading the words more slowly).

\section{Cognitive flexibility}

The greater number of perseverative errors made on the WCST by our bipolar $(+\mathrm{P})$ group compared with the healthy relative group is consistent with the finding of Bora et al that patients with a history of psychosis obtained fewer categories on the WCST than patients with bipolar disorder but no psychosis. ${ }^{12}$ It is also congruent with studies noting a greater number of WCST perseverative errors in adults with schizotypal personality disorder ${ }^{47}$ as well as in the adolescent offspring of people with schizophrenia compared with healthy controls. ${ }^{48}$ Perseveration can be regarded as a so-called 'bias against disconfirmatory evidence', a trait reportedly indicative of vulnerability to schizophrenia. ${ }^{49}$ This trait has been reported to be salient in a non-clinical sample with high scores on the SPQ. ${ }^{49}$

\section{Schizotypal personality traits and neurocognitive function}

A methodological weakness of previous studies has been the exclusive reliance on DSM-IV criteria. As Glahn et al noted, ${ }^{11}$ an alternative, quantitative method of modelling psychotic features may be a better method of testing cognition-psychosis relationships than the traditional 'yea or nay' method of labelling people based on the SCID-I. Obtaining a valid quantitative measure of a history of psychotic features is difficult, however, and essentially suffers from the same weakness as a dichotomous retrospective diagnosis of a history of psychosis. We therefore also made use of an alternative approach, namely quantifying the level of schizotypal personality traits in our sample. Schizotypal personality traits theoretically reflect an individual's vulnerability to psychotic breakdown and by extension a genetic liability to schizophrenia. ${ }^{50}$ These personality characteristics have been shown to cluster in the unaffected relatives of patients with schizophrenia in one study, ${ }^{51}$ together with cognitive impairment. ${ }^{52}$ Further, pre-emptive treatment of these vulnerable population groups with antipsychotic medication has met with some success. ${ }^{53}$

\section{Working memory}

The significant negative association between scores on the STA and performance on the reverse Digit Span complements our finding that the DSM-IV-defined bipolar $(+\mathrm{P})$ group, but not the bipolar $(-\mathrm{P})$ group, performed significantly more poorly than unaffected relatives on the Digit Span task $(P=0.0066$ and $P=0.1608$ respectively). It is also consistent with neuropsychological studies of high-risk populations displaying schizotypal personality traits.

Working memory impairment as measured by digit span, ${ }^{54}$ the delayed alternation task, ${ }^{55}$ the dot task, ${ }^{56}$ the paced auditory serial attention test ${ }^{37}$ and a test of visual working memory, ${ }^{57}$ has been reported in patients with schizotypal personality disorder. In fact, spatial working memory impairment has been reported to constitute an endophenotypic marker for vulnerability to psychotic breakdown. ${ }^{58}$ Congruent with these data, self-report measures of schizotypal personality traits have also been shown to predict working memory performance. Performance on a spatial working memory task was found by Park et al to be more impaired in people who scored higher on the Perceptual Aberration Scale ${ }^{5}$ and a follow-up study replicated this effect with the SPQ. ${ }^{59}$ More recently, Kopp noted a deficit in the executive control of working memory in participants scoring highly on the SPQ. ${ }^{60}$

\section{Visual memory}

Visual memory dysfunction per se is not generally regarded as a particularly salient feature of the schizotypal personality disorder cognitive profile, ${ }^{61}$ although some studies have certainly noted impairments. ${ }^{1,2}$ Nevertheless, the positive association between STA scores and RCF performance in our sample is counterintuitive and is not supported by the literature. We raise the possibility that this is a false positive result.

\section{Verbal declarative memory}

The negative association between STA scores and scores obtained on the learning rate sub-test of the RAVLT is consistent with a meta-analysis of 20 studies examining verbal memory function in first-degree relatives of people with schizophrenia, which reported impairment in verbal declarative memory with a small to moderate effect size. ${ }^{62}$

In conclusion, we find no evidence that 'psychotic' and 'nonpsychotic' subtypes of bipolar disorder are qualitatively different from each other in terms of their cognitive function. Nevertheless, the two putative subtypes of bipolar disorder appear to be quantitatively different, suggesting that they may lie on a nosological continuum most clearly defined by degree of verbal working and declarative memory impairment.

\section{Strengths of the study}

In this study we used three original strategies.

(a) Schizotypal personality traits, which are postulated to be indicative of a vulnerability to psychotic breakdown, were used as a quantitative predictor of neurocognitive function. Thus, we obtained convergent results with two different measures of the psychotic bipolar disorder 'subtype'.

(b) Childhood trauma, which is associated with psychotic symptoms and cognitive dysfunction, was measured and controlled for, possibly improving the accuracy of our results compared with previous studies.

(c) Our family-based design not only makes it more likely that our three comparison groups came from similar cultural 
and socio-economic backgrounds, but also may have decreased genetic heterogeneity across the sample.

\section{Limitations}

It would have been useful to have recruited a comparison group of people with schizophrenia to compare with our bipolar $(+\mathrm{P})$ group. Similarly, our two bipolar disorder groups might have differed more sharply from a group of unrelated healthy controls than from their unaffected relatives. Second, given the evidence for working memory deficits in schizophrenia and in bipolar disorder with a history of psychosis, our study would have benefited from a more thorough interrogation of working memory. For example, a test of visual working memory would have strengthened our conclusions. Third, we made use of only one measure of schizotypal personality traits - the STA. Schizotypy encompasses a heterogeneous collection of traits and the STA does not differentiate between positive, negative and disorganised aspects of schizotypy. It is, therefore, conceivable that different results would have been obtained using another questionnaire.

Although our sample size compares favourably with those in other studies, ${ }^{11,12,41,63}$ it is conceivable that a larger sample size would have further differentiated the psychosis from the nonpsychosis groups. Other limitations are that psychosis may not be a unitary construct - in other words, heterogeneous patterns of psychotic symptoms may differentially affect neurocognition and course of illness. No follow-up SCID-I interviews were carried out after the initial wave of the study and, thus, the possibility exists that some of the participants' diagnoses would have changed in the intervening period. Finally, our sample was selected for a genetic loading towards bipolar disorder and therefore our results may not be generalisable to sporadic populations.

\section{Future work}

Given the difficulty of comprehensively controlling for confounding variables in cross-sectional analyses, well-controlled prospective studies that follow at-risk individuals prior to the onset of illness are the optimal way to assess phenotypic differences between people with bipolar disorder with and without psychotic features. Another possible strategy to reduce genetic and phenotypic heterogeneity is to recruit extended families with a high density of affected individuals. An example of this approach can be seen in our earlier study. ${ }^{46}$ Ideally, a large extended family with a high density of psychotic bipolar disorder could be compared with a family with a milder, non-psychotic form of bipolar disorder.

\footnotetext{
Jonathan Savitz, Division of Human Genetics, Institute of Infectious Disease and Molecular Medicine, University of Cape Town; Lize van der Merwe, Biostatistics Unit, Medical Research Council of South Africa; Dan J. Stein, Department of Unit, Medical Research Council of South Africa; Dan J. Stein, Department of
Psychiatry, Mark Solms, Departments of Psychology and Neurology, University of Cape Town; Rajkumar Ramesar, Division of Human Genetics, Institute of Infectious Disease and Molecular Medicine, University of Cape Town, Cape Town, South Africa

Correspondence: Jonathan Savitz, Room 200, B15K, North Drive, National Institutes of Health, Bethesda, MD 20892, USA. Email: savitzj@mail.nih.gov

First received 3 Mar 2008, final revision 24 Jun 2008, accepted 1 Sep 2008
}

\section{Acknowledgements}

The support of the Medical Research Council of South Africa and the University of Cape Town Brain and Behaviour Initiative is acknowledged. We thank Elize Pietersen and Gameda Benefeld for conducting psychological interviews.

\section{References}

1 Savitz J, Solms M, Ramesar R. Neuropsychological dysfunction in bipolar affective disorder: a critical opinion. Bipolar Disord 2005; 7: 216-35.

2 Robinson LJ, Thompson JM, Gallagher P, Goswami U, Young AH, Ferrier IN, et al. A meta-analysis of cognitive deficits in euthymic patients with bipolar disorder. J Affect Disord 2006; 93: 105-15.

3 Savitz JB, van der Merwe L, Stein DJ, Solms M, Ramesar RS. Neuropsychological task performance in bipolar spectrum illness: genetics, alcohol abuse, medication and childhood trauma. Bipolar Disord 2008; 10: 479-94.

4 Savitz J, van der Merwe L, Stein DJ, Solms M, Ramesar R. Genotype and childhood sexual trauma moderate neurocognitive performance: a possible role for brain-derived neurotrophic factor and apolipoprotein E variants. Biol Psychiatry 2007; 62: 391-9.

5 Park S, Holzman PS, Goldman-Rakic PS. Spatial working memory deficits in the relatives of schizophrenic patients. Arch Gen Psychiatry 1995; 52: 821-8.

6 American Psychiatric Association. Diagnostic and Statistical Manual of Mental Disorders (4th edn) (DSM-IV). APA, 1994.

7 Keck PE, McElroy SL, Havens JR, Altshuler LL, Nolen WA, Frye MA, et al. Psychosis in bipolar disorder: phenomenology and impact on morbidity and course of illness. Compr Psychiatry 2003; 44: 263-9.

8 Rossi A, Daneluzzo E. Schizotypal dimensions in normals and schizophrenic patients: a comparison with other clinical samples. Schizophr Res 2002; 54: 67-75.

9 Heron J, Jones I, Williams J, Owen MJ, Craddock N, Jones LA, et al. Selfreported schizotypy and bipolar disorder: demonstration of a lack of specificity of the Kings Schizotypy Questionnaire. Schizophr Res 2003; 65: 153-8.

10 Schurhoff F, Laguerre A, Szoke A, Meary A, Leboyer M. Schizotypal dimensions: continuity between schizophrenia and bipolar disorders. Schizophr Res 2005; 80: 235-42.

11 Glahn DC, Bearden CE, Barguil M, Barrett J, Reichenberg A, Bowden CL, et al. The neurocognitive signature of psychotic bipolar disorder. Biol Psychiatry 2007; 621: 910-6.

12 Bora E, Vahip S, Akdeniz F, Gonul AS, Eryavuz A, Ogut M, et al. The effect of previous psychotic mood episodes on cognitive impairment in euthymic bipolar patients. Bipolar Disord 2007; 9: 468-77.

13 Claridge G, Broks P. Schizotypy and hemisphere function - I. Personal Individ Diff 1984; 5: 633-48.

14 First M, Spitzer R, Gibbon M. Structured Clinical Interview for DSM -IV Axis I Disorders. American Psychiatric Press, 1991.

15 Beck AT, Steer RA. Manual for the Beck Depression Inventory. Psychological Corporation, 1993.

16 Altman EG, Hedeker D, Peterson JL, Davis JM. The Altman Self-Rating Mania Scale. Biol Psychiatry 1997; 42: 948-55.

17 Claasen NCW, Krynauw AH, Mathe M, Paterson H. A Standardisation of the WAIS-III for English-speaking South Africans. Human Sciences Research Council, 2001.

18 Spreen O, Strauss E. A Compendium of Neuropsychological Tests. Oxford University Press, 1991.

19 Bernstein DP, Stein JA, Newcomb MD, Walker E, Pogge D, Anluvalia T, et al. Development and validation of a brief screening version of the Childhood Trauma Questionnaire. Child Abuse Negl 2003; 27: 169-90.

20 Prescott A, Bank L, Reid JB, Knutson JF, Burraston BO, Eddy JM, et al. The veridicality of punitive childhood experiences reported by adolescents and young adults. Child Abuse Neg/ 2000; 24: 411-23.

21 Jackson M, Claridge G. Reliability and validity of a psychotic traits questionnaire (STQ). Br J Clin Psychol 1991; 30: 311-23.

22 Pilia G, Chen WM, Scuteri A, Orru M, Albai G, Dei M, et al. Heritability of cardiovascular and personality traits in 6,148 Sardinians. PLOS Genet 2006; 2: e132.

23 Yildiz A, Sachs GS. Age onset of psychotic versus non-psychotic bipolar illness in men and in women. $J$ Affect Disord 2003; 74: 197-201.

24 Mann JJ, Bortinger J, Oquendo MA, Currier D, Li S, Brent DA, et al. Family history of suicidal behavior and mood disorders in probands with mood disorders. Am J Psychiatry 2005; 162: 1672-9.

25 Read J, van Os J, Morrison AP, Ross CA. Childhood trauma, psychosis and schizophrenia: a literature review with theoretical and clinical implications. Acta Psychiatr Scand 2005; 112: 330-50.

26 Neria Y, Bromet EJ, Carlson GA, Naz B. Assaultive trauma and illness course in psychotic bipolar disorder: findings from the Suffolk county mental health project. Acta Psychiatr Scand 2005; 111: 380-3. 
27 Hammersley P, Dias A, Todd G, Bowen-Jones K, Reilly B, Bentall RP. Childhood trauma and hallucinations in bipolar affective disorder: preliminary investigation. Br J Psychiatry 2003; 182: 543-7.

28 Startup M. Schizotypy, dissociative experiences and childhood abuse: relationships among self-report measures. Br J Clin Psychol 1999; 38: 333-44.

29 Berenbaum H, Valera EM, Kerns JG. Psychological trauma and schizotypal symptoms. Schizophr Bull 2003; 29: 143-52.

30 Squires-Wheeler E, Skodol AE, Bassett A, Erlenmeyer-Kimling L. DSM-III-R schizotypal personality traits in offspring of schizophrenic disorder, affective disorder, and normal control parents. J Psychiatr Res 1989; 23: 229-39.

31 Chapman LJ, Chapman JP, Kwapil TR, Eckblad M, Zinser MC. Putatively psychosis-prone subjects 10 years later. J Abnorm Psychol 1994; 103: 171-83.

32 Cousins DA, Young AH. The armamentarium of treatments for bipolar disorder: a review of the literature. Int J Neuropsychopharmacol 2007; 10 411-31

33 Ferrier IN, Chowdhury R, Thompson JM, Watson S, Young AH. Neurocognitive function in unaffected first-degree relatives of patients with bipolar disorder: a preliminary report. Bipolar Disord 2004; 6: 319-22.

34 Bowie CR, Harvey PD. Cognition in schizophrenia: impairments, determinants, and functional importance. Psychiatr Clin North Am 2005; 28 613-33.

35 Lee J, Park S. Working memory impairments in schizophrenia: a metaanalysis. J Abnorm Psychol 2005; 114: 599-611.

36 Trandafir A, Meary A, Schurhoff F, Leboyer M, Szoke A. Memory tests in firstdegree adult relatives of schizophrenic patients: a meta-analysis. Schizophr Res 2006; 81: 217-26.

37 Mitropoulou V, Harvey PD, Zegarelli G, New AS, Silverman JM, Siever L, et al. Neuropsychological performance in schizotypal personality disorder: importance of working memory. Am J Psychiatry 2005; 162: 1896-903.

38 Torrent C, Martínez-Arán A, Daban C, Sánchez-Moreno J, Comes M, Goikolea JM, et al. Cognitive impairment in bipolar II disorder. Br J Psychiatry 2006; 189: 254-9.

39 Taylor Tavares JV, Clark L, Cannon DM, Erickson K, Drevets WC, Sahakian BJ, et al. Distinct profiles of neurocognitive function in unmedicated unipolar depression and bipolar II depression. Biol Psychiatry 2007; 62: 917-24.

40 Robinson LJ, Ferrier IN. Evolution of cognitive impairment in bipolar disorder: a systematic review of cross-sectional evidence. Bipolar Disord 2006; 8: 103-16.

41 Martinez-Aran A, Vieta E, Reinares M, Colom F, Torrent C, Sanchez-Moreno J, et al. Cognitive function across manic or hypomanic, depressed, and euthymic states in bipolar disorder. Am J Psychiatry 2004; 161: 262-70.

42 Martinez-Aran A, Torrent C, Tabares-Seisdedos R, Salamero M, Daban C, Balanza-Martinez $\mathrm{V}$, et al. Neurocognitive impairment in bipolar patients with and without history of psychosis. J Clin Psychiatry 2008; 69: 233-9.

43 Kieseppa T, Tuulio-Henriksson A, Haukka J, Van Erp T, Glahn D, Cannon TD, et al. Memory and verbal learning functions in twins with bipolar-I disorder, and the role of information-processing speed. Psychol Med 2005; 35: 205-15.

44 Ali SO, Denicoff KD, Altshuler LL, Hauser P, Li X, Conrad AJ, et al. A preliminary study of the relation of neuropsychological performance to neuroanatomic structures in bipolar disorder. Neuropsychiatry Neuropsychol Behav Neurol 2000; 13: 20-8.

45 Zalla T, Joyce C, Szoke A, Schurhoff F, Pillon B, Komano O, et al. Executive dysfunctions as potential markers of familial vulnerability to bipolar disorde and schizophrenia. Psychiatry Res 2004; 121: 207-17.
46 Savitz J, van der Merwe L, Solms M, Ramesar R. Neurocognitive function in an extended Afrikaner-ancestry family with affective illness. J Psychiatry Neurosci 2007; 32: 116-20.

47 Diforio D, Walker EF, Kestler LP. Executive functions in adolescents with schizotypal personality disorder. Schizophr Res 2000; 42: 125-34.

48 Diwadkar VA, Montrose DM, Dworakowski D, Sweeney JA, Keshavan MS Genetically predisposed offspring with schizotypal features: an ultra high-risk group for schizophrenia? Prog Neuropsychopharmacol Biol Psychiatry 2006; 30: $230-8$.

49 Buchy L, Woodward TS, Liotti M. A cognitive bias against disconfirmatory evidence (BADE) is associated with schizotypy. Schizophr Res 2007; 90: 334-7.

50 Kendler KS, Walsh D. Schizotypal personality disorder in parents and the risk for schizophrenia in siblings. Schizophr Bull 1995; 21: 47-52.

51 Appels MC, Sitskoorn MM, Vollema MG, Kahn RS. Elevated levels of schizotypal features in parents of patients with a family history of schizophrenia spectrum disorders. Schizophr Bull 2004; 30: 781-90.

52 Nuechterlein KH, Asarnow RF, Subotnik KL, Fogelson DL, Payne DL, Kendler KS, et al. The structure of schizotypy: relationships between neurocognitive and personality disorder features in relatives of schizophrenic patients in the UCLA Family Study. Schizophr Res 2002; 54: 121-30.

53 McGorry PD, Yung AR, Phillips L. The 'close-in' or ultra high-risk model: a safe and effective strategy for research and clinical intervention in prepsychotic mental disorder. Schizophr Bull 2003; 29: 771-90.

54 Squires-Wheeler E, Friedman D, Amminger GP, Skodol A, Looser-Ott S, Roberts $\mathrm{S}$, et al. Negative and positive dimensions of schizotypal personality disorder. J Personal Disord 1997; 11: 285-300.

55 Dickey CC, McCarley RW, Xu ML, Seidman $\sqcup$, VogImaier MM, Niznikiewicz MA, et al. MRI abnormalities of the hippocampus and cavum septi pellucidi in females with schizotypal personality disorder. Schizophr Res 2007; 89: 49-58.

56 Roitman SE, Cornblatt BA, Bergman A, Obuchowski M, Mitropoulou V, Keefe RS, et al. Attentional functioning in schizotypal personality disorder. Am J Psychiatry 1997; 154: 655-60.

57 Farmer CM, O’Donnell BF, Niznikiewicz MA, Voglmaier MM, McCarley RW, Shenton $\mathrm{ME}$, et al. Visual perception and working memory in schizotypal personality disorder. Am J Psychiatry 2000; 157: 781-8.

58 Wood SJ, Pantelis C, Proffitt T, Phillips $\amalg$, Stuart GW, Buchanan JA, et al. Spatial working memory ability is a marker of risk-for-psychosis. Psychol Med 2003; 33: 1239-47.

59 Park S, McTigue K. Working memory and the syndromes of schizotypal personality. Schizophr Res 1997; 26: 213-20.

60 Kopp B. Mnemonic intrusions into working memory in psychometrically identified schizotypal individuals. J Behav Ther Exp Psychiatry 2007; 38: 56-74.

61 Myles-Worsley M, Ord LM, Ngiralmau H, Weaver S, Blailes F, Farone SV. The Palau Early Psychosis Study: neurocognitive functioning in high-risk adolescents. Schizophr Res 2007; 89: 299-307.

62 Whyte MC, McIntosh AM, Johnstone EC, Lawrie SM. Declarative memory in unaffected adult relatives of patients with schizophrenia: a systematic review and meta-analysis. Schizophr Res 2005; 78: 13-26.

63 Selva G, Salazar J, Balanza-Martinez V, Martinez-Aran A, Rubio C, Daban C, et al. Bipolar I patients with and without a history of psychotic symptoms: do they differ in their cognitive functioning? J Psychiatr Res 2007; 41: 265-72. 